\title{
ÉTICA NA EDUCAÇÃO
}

\section{ETHICAL IN EDUCATION}

Patrícia Aparecida Tadêus ${ }^{1}$

Orientadora: Prof $^{a}$ Nilda Abadia Frazão Cunha ${ }^{2}$

\begin{abstract}
Resumo: Este artigo apresenta algumas reflexões sobre a Ética na formação docente, à luz teórica de autores, como: Candau (1988), Chauí (1988), Freire (1996), Morin (2005), Hernandez (1998), Vasquez (1998), entre outros. Foram discutidas e questionadas temáticas como: a questão da ética na formação do educador, bem como as relações interpessoais no desenvolvimento do trabalho pedagógico que envolve o respeito mútuo, o diálogo, a solidariedade e a justiça. $O$ compromisso da escola frente às responsabilidades éticas desempenha um debate fundamental em torno da qualidade da prática docente. Ressalta-se, neste sentido, a intenção dos Parâmetros Curriculares Nacionais - PCNs (BRASIL, 1997) que apresenta nos chamados "temas transversais: Ética, Pluralidade Cultural, Meio Ambiente, Orientação Sexual e Saúde", a visão sobre o papel da escola no contexto atual, partindo da preocupação em se formar o cidadão para viver plenamente em sociedade. Trata-se de uma preocupação com a formação docente, em um momento em que a escola vive grandes transformações de acordo com o contexto em que está inserida, que prevê a inclusão de novos temas a partir da relação pedagógica e do seu contexto social. Sem dúvida, estamos diante de uma inovação, num cenário de mudanças aceleradas no novo milênio, e que por isso, se faz urgente um educador disposto a atuar numa sociedade terrena e humana com responsabilidade ética.
\end{abstract}

Palavras-chave: Ética. Formação Docente. Compromisso.

Abstract: This article aims to present some reflections on Ethics in teaching education from authors such as: Candau (1988), Chauí (1988), Freire (1996), Morin (2005), Hernandez (1998), among others. We discuss the question of ethics in educators' education, as well as interpersonal relations in the development of the pedagogical work that involves mutual respect, dialogue, solidarity and justice. The commitment of the school to the ethical responsibilities creates a basic debate around the quality of practical professor. We must emphasize the aim of National Curricular Parameters - PCN's (BRAZIL, 1997) that presents in the so-called "transversal subjects" Ethics, Cultural Plurality, Environment, Orientation Sexual and Health, the vision on the role of schools in the current context, with the concern of educating citizens to live fully in society. There is a concern about teachers' education, at a moment where schools suffers broad transformations in accordance to the context where it is inserted, which aims at the inclusion of new subjects from the pedagogical relation and its social context. No doubt we are before an innovation, in a scenery of changes sped up in the new millennium, and that therefore makes urgent educators able to act in a secular society and human beings with ethical responsibility.

Keywords: Ethics. Teaching Formation. Commitment.

\footnotetext{
${ }^{1}$ Especialista em Docência na Educação Superior pela Universidade Federal Triângulo Mineiro (UFTM). E-mail: pitici33@hotmail.com

2 UNIPAC. E-mail: nilda.frazao@hotmail.com
} 


\section{Introdução}

A relação fundamental da ética no desenvolvimento educacional na pósmodernidade está diretamente relacionada ao serviço da escola que deve ser a formação integral do aluno. Tal conjuntura reflete na formação ética do educador.

A ética é indispensável em todos os aspectos da vida profissional docente e visando esta importância, este artigo tem como objetivo investigar sobre a necessidade da formação ética do educador, compreendida, vivenciada e exercida também na prática pelo corpo pedagógico, orientador, administrativo, funcional e discente da escola. A formação ética tem uma grande e determinante influência na vida pessoal de todos os segmentos da escola, refletindo em sua desenvoltura e responsabilidade no contexto cultural em que está inserida.

Nesse sentido, o interesse pelo tema Ética na educação surgiu também da necessidade de realizar um estudo mais aprofundado sobre essa questão, sobretudo neste início de século em que existe uma inversão de valores e, portanto, uma crise no que diz respeito aos valores morais e humanos.

O tema ética na educação não é novo, mas foi com os Parâmetros Curriculares Nacionais (PCNs) e o estudo de alguns teóricos como Paulo Freire, que iniciaram uma nova proposta para a sala de aula, redirecionando as diretrizes que valorizam o aluno, suas múltiplas inteligências, sua realidade, suas concepções prévias, sua produção, em um espaço dialógico-lúdico, atendendo as exigências do novo cenário sócio-educacional, transformando o aprendizado em algo significativo, contextualizado e fundamentado.

Sabemos que o homem vive em sociedade, convive com outros homens e, por isso lhe cabe pensar e se interrogar: Como devo agir essencialmente diante dos outros homens? Trata-se de uma pergunta fácil de ser formulada mas difícil de ser respondida. Quanto a isso, alguns teóricos ao longo da história identificaram a ética como conjunto de princípios e padrões de conduta, logo dão importância ao pensamento reflexivo sobre os valores e as normas que regem as condutas humanas desde os primórdios dos tempos.

Partindo desse princípio, a abordagem feita sobre a importância de uma atuação docente com ética, neste trabalho, parte da necessidade de realizar uma prática pedagógica embasada em princípios éticos, pois se o homem não pode 
mudar o seu patrimônio genético, ele pode mudar seu ambiente, assim como pode mudar suas formas de reação, ante as manifestações do meio em que se encontra.

É evidente a importância de se ter incorporados os Temas Transversais, relacionados à ética como parte dos conteúdos educativos, para que educadores e educandos possam questionar, criticar, analisar e consequentemente transformar sua conduta, baseados por uma educação que se preocupa consensualmente com a cidadania.

É relevante destacar que o professor contemporâneo constrói seu perfil profissional em uma sociedade globalizada, onde as aceleradas inovações científicotecnológicas têm exigido-lhe novos saberes, habilidades e atitudes que lhe possibilite dialogar, adaptar e intervir em uma realidade educativa diversa e transitória. Sob essa ótica, compreende-se, que o eixo central da formação docente é a mudança, e que ser professor não é apenas participar de uma etapa, mas entender que sua formação é um processo contínuo e permanente de aprendizagem.

A formação ética do educador preconiza a valorização dos conhecimentos e experiências dos alunos; analisa problemas e busca soluções, estimula a criticidade, a curiosidade e a flexibilidade mental para novas formas de resolver os conflitos. Esse profissional se preocupa com a formação de sujeitos, efetivando o ensinar e o apreender, a partir de valores, da heteronomia para a autonomia, de pessoas dependentes para independentes.

Assim, para viver neste contexto desafiador e envolvente, é preciso superar a atuação personalista, solitária e individualista dos docentes, bem como a valorização do conhecimento do saber do estudante, abolindo a herança de "professor enciclopédia", de visão compartimentada.

Um dos principais objetivos da educação é ensinar valores e esses são incorporados pelo aluno desde muito cedo. É preciso mostrar-lhe como compreender a si mesmo para que possa compreender os outros e a humanidade em geral.

Segundo Morin (2005, p. 56), "os jovens têm de conhecer as particularidades do ser humano e o papel dele na era planetária que vivemos". Por isso a educação precisa fazer a sua parte, incorporando essas discussões, sem fragmentar a 
realidade, mas simplificando o complexo e enxergando a multiplicidade e a diversidade presentes na educação atual.

Sendo a ética determinante procedimental e atitudinal, a educação atual tem como objetivo a comunicação, por meio de estratégias integradoras, visando fim comum, ou seja, a escola facilitando o acesso, meios, oportunidades, mobilizando individual e coletivamente, identificando limites e possibilidades, organizando o ambiente físico e psicológico com o grupo de trabalho, desafiando, por meios diversos, o cuidado ao responder e ao lidar com as respostas.

Dessa forma, definir a ação docente para atuar frente às novas mudanças, nos leva à compreensão de que a sua formação, deve ser constituída por meio de uma vertente de qualidade, ou seja, com o caráter ético da atividade docente do professor, como profissional e pesquisador.

\section{Fundamentação teórica}

Falar em formação ética do educador exige compreender alguns conceitos como a origem da palavra ética, por exemplo. A palavra ética se origina diretamente do latim ethica, e, indiretamente, do grego ฤӨıкń, que apresentam vários significados como: costume ou hábito; morada, estância, residência, o abrigo permanente, casa; caráter, índole natural, temperamento, conjunto de disposições físicas e psíquicas de uma pessoa (VÁZQUEZ, 1998). Este sentido refere-se à conduta humana suscetível de qualificação do ponto de vista do bem e do mal.

Neste contexto, é importante ressaltar que existe uma confusão entre as palavras Ética e Moral, que vem perpetuando há séculos. Esta confusão pode ser resolvida com o esclarecimento dos dois temas, sendo que Moral é um conjunto de normas que regulam o comportamento do homem em sociedade, e estas normas são adquiridas pela educação, pela tradição e pelo cotidiano. Durkheim explicava Moral como a "ciência dos costumes", sendo algo anterior a própria sociedade. A Moral tem caráter obrigatório. Já a palavra Ética, Motta (1984) define como um conjunto de valores que orientam o comportamento do homem em relação aos outros homens na sociedade em que vive, garantindo, outrossim, o bem-estar social, ou seja, Ética é a forma que o homem deve se comportar no seu meio social. 
A Moral sempre existiu, pois todo ser humano possui a consciência Moral que o leva a distinguir o bem do mal no contexto em que vive. Surgindo realmente quando o homem passou a fazer parte de agrupamentos, isto é, surgiu nas sociedades primitivas, nas primeiras tribos. A Ética teria surgido com Sócrates, quando o filósofo investiga e explica as normas morais que o leva a agir não só por tradição, educação ou hábito, mas principalmente por convicção e inteligência.

Vásquez (1998) aponta que a Ética é teórica e reflexiva, enquanto a Moral é eminentemente prática. Uma completa a outra, havendo um inter-relacionamento entre ambas, pois na ação humana, o conhecer e o agir são indissociáveis.

Dessa forma, a ética é indispensável em todos os aspectos da vida, seja profissional ou social, no tempo presente e no futuro, visando tanto a realização pessoal quanto as convivências sociais.

Em relação à formação docente e a ética, muitos estudos direcionados à concepção, análise e contextualização demonstram que as condições desta formação continuam deficitárias em termos de diferenciações na organização e gestão das práticas docentes, se limitando a uma dimensão individual, e nunca interpessoal e compartilhada como preconiza os conceitos éticos.

Dessa forma, é necessário, nos dias atuais, que o professor invista em sua formação, para que ele possa aprimorar e reconstruir seus saberes, muitas vezes vindos de uma educação tradicional, o que deixa de demonstrar seus valores sociais, éticos, culturais e epistemológicos que não se relacionam diretamente à sua capacidade permanente de renovação.

Considera-se, portanto, a necessidade de se pensar a formação docente sob uma perspectiva ética.

\section{A questão da ética na formação do educador}

Entende-se que ética, pela própria etimologia, diz respeito a uma realidade humana que é construída histórica e socialmente a partir das relações coletivas dos seres humanos nas sociedades onde nascem e vivem.

Para Morin (2005), a ética, na escola, não poderia ser ensinada por meio de lições de moral. Deve formar-se nas mentes com base na consciência de que o 
humano é, ao mesmo tempo, indivíduo, parte da sociedade, parte da espécie. Carregamos em nós esta tripla realidade e por isso, todo desenvolvimento verdadeiramente humano deve compreender o desenvolvimento conjunto das autonomias individuais, das participações comunitárias e da consciência de pertencer à espécie humana.

Partindo disso, é importante na educação duas grandes finalidades éticopolíticas para o novo milênio: estabelecer uma relação de controle mútuo entre a sociedade e os indivíduos pela democracia e conceber a humanidade como comunidade planetária. A educação deve contribuir não somente para a tomada de consciência de nossa "Terra-Pátria", mas também permitir que esta consciência se traduza em vontade de realizar a cidadania terrena (MORIN, 2005).

Na condição de seres humanos não possuímos as chaves para abrirem as portas de um futuro melhor, como também não conhecemos o caminho a ser traçado, mas, podemos, explicitar nossas finalidades: "a busca da hominização na humanização, pelo acesso à cidadania terrena" (MORIN, 2005, p. 45). Nesse sentido, a ética trata-se de uma aprendizagem que resulta em aprender a resolver conflitos por meio do diálogo, aprender a ser solidário, a ajudar, a ser democrático, a dizer o que pensa, a ouvir e a respeitar os outros.

De acordo com Chauí (1988, p. 45), o filósofo Sócrates, "acreditava que bastava saber o que é bondade para ser bom". Entretanto, o pressuposto básico da Ética de Sócrates - que basta saber o que é bondade para que se seja bom - parece ingênuo no mundo de hoje, onde já está profundamente gravado na nossa mente que só algum grau de coerção é capaz de evitar que o homem seja mau. Na época de Sócrates, isso se baseava numa "noção perfeitamente coerente com o pensamento - ainda que não com a prática - da sociedade grega" (CHAUí, 1988, p. 45). Antes de Sócrates não teria havido uma reflexão organizada sobre a ética e o homem, por isso, é inegável que ele seja o "Pai da Ética". Desde então, todos os grandes pensadores trouxeram valiosas contribuições para uma vivência coerente da ética: Platão, Aristóteles, Agostinho, Tomás de Aquino, Spinosa, Kant, Nietzsche e tantos outros têm brilhantes páginas sobre a conduta humana.

Segundo Chauí (1988),

Para a filosofia, o comportamento ético é aquele que é considerado bom, e, sobre a bondade, os antigos diziam que: o que é bom para a leoa, não pode ser bom à gazela. $E$, o que é bom à gazela, fatalmente não será bom à leoa. Este é um dilema ético típico (CHAUI, 1988, p. 89). 
Dessa forma, compreende-se que o objetivo de uma teoria da ética é determinar o que é bom, tanto para o indivíduo como para a sociedade como um todo. Os filósofos antigos adotaram diversas posições na definição do que é bom, sobre como lidar com as prioridades em conflito dos indivíduos versus o todo, sobre a universalidade dos princípios éticos.

Para Hernandez (1988):

\begin{abstract}
O homem vive em sociedade, convive com outros homens e, portanto, cabe-lhe pensar e responder à seguinte pergunta: "Como devo agir perante os outros?". Trata-se de uma pergunta fácil de ser formulada, mas difícil de ser respondida. Ora, esta é a questão central da Moral e da Ética. Enfim, a ética é julgamento do caráter moral de uma determinada pessoa (HERNANDEZ, 1988, p. 98).
\end{abstract}

Com isso, a ética tem sido aplicada na economia, política e ciência política (também tem sido aplicada à estrutura da família, à sexualidade, e como a sociedade vê o papel dos indivíduos), conduzindo a campos distintos e nãorelacionados, como o feminismo e a guerra, por exemplo.

Em relação à educação, a ética constitui-se um dos temas transversais propostos nos Parâmetros Curriculares Nacionais (PCNs/MEC, 1997) e reflete a preocupação para que a escola realize um trabalho que incentive a autonomia na constituição de valores de cada aluno, ajudando-o a se posicionar nas relações sociais dentro da escola e da comunidade como um todo.

Com base neste tema, não podemos nos esquecer que estamos vivendo um momento histórico muito oportuno para a reflexão e a ação em prol da formação ética docente. Para evidenciar as múltiplas dimensões que a tarefa docente impõe, Freire afirma ser inerente ao papel do educador "não apenas ensinar os conteúdos, mas também ensinar a pensar certo". Esse pensar certo, por sua vez remete a uma busca de leitura da realidade que deve permanecer vinculada à pureza, "à rigorosidade ética e deve ser também geradora de boniteza, logo tem uma dimensão estética e criadora" (FREIRE, 1996, p. 30). Lógica, ética e estética, são conceitos que se entrelaçam, indissociáveis no contexto mais amplo das concepções singulares do pensamento freireano.

Acredita-se que só uma educação de qualidade, que ensina os princípios básicos da ética, pode vir a ajudar os alunos a responder à pergunta fundamental da existência: como viver? Ou seja, como ajudá-los a responder a esta pergunta por si 
mesmos, serem autores de suas escolhas, aprendendo a responsabilizar-se por elas? Como ajudá-los a se construírem autonomamente e se tornarem adultos éticos? Como ajudá-los, enfim, a viver num mundo em constante mudança sem perderem a si mesmos?

Devido à urgência de estabilização social, a ética e a educação para os valores passaram a representar um dos grandes eixos de preocupação e discussão nos mais diversos campos: político, científico, religioso, e, especialmente, no campo educacional.

Freire, nas suas últimas obras, Pedagogia da Autonomia e Pedagogia da Indignação, de modo incisivo esboça os traços daquilo que ele mesmo nomeou de ética universal e denunciou um mundo marcado pelas malvadezas de uma ética do mercado:

[...] pelas violências de toda sorte, é necessário retomar esta temática, que não somente interessa aos pedagogos, mas a todos os cidadãos preocupados com uma ação-intervenção no mundo que resgate a eticidade, a boniteza, a dignidade de homens e mulheres (FREIRE, 1996, p. 31).

Para Freire, ensinar a ética é poder perceber as virtudes que são exigidas ao ato de ensinar e aprender, que não são poucas. E como ele mesmo propõe, "deve-se lutar por uma ética inseparável da prática educativa" e, esta luta se manifestará na prática diária; para tanto é necessário "testemunhá-la, vivaz, aos educandos em nossas relações com eles" (FREIRE, 1996, p. 17).

[...] A nossa práxis educativa, em sua incessante e dialógica interação saber-prática, teoria-ação, não deve senão aspirar à plenitude e à inteireza de todos os seus contornos, planuras e saliências, de todos os seus aspectos, incluso aqui o ético-moral; de nossa inserção e presença no mundo do outro e com o outro (FREIRE, 1996, p. 29).

Cabe à educação o papel de mensageira de esperança, de uma educação que não transgride as questões éticas, mas que dirija suas ações educativas no sentido de que o educando, responsável pelo seu autoconhecimento, construa valores éticos, tão indispensáveis para a vida em sociedade. 


\section{As relações interpessoais e éticas no desenvolvimento do trabalho pedagógico}

Em todas as atividades humanas, é importante que haja transformações em prol da humanidade, ou seja, no desenvolvimento da atividade de uns a serviço dos outros. A atuação do homem pode ser apenas uma ação mecânica, automática movida pelo instinto, com finalidades exclusivamente materiais e imediatas ou uma ação humanitária, planejada, movida pela vontade, pelo coração e pela consciência.

Nesse contexto, é necessário que o homem seja educado e receba uma formação ética que o faça ter respeito e consideração por todos os seus semelhantes, como também pela natureza em que vive.

É pelo processo de formação educativa que o homem chega a um nível aceitável de formação intelectual e profissionalizante. Quanto a isso, cabe à escola desenvolver um processo de ensino-aprendizagem, que contemple atividades de cunho vital e psicológico, que exerça motivação e estimulo para sua participação, num ambiente saudável, alegre, criativo e responsável. Nesse sentido, pode-se afirmar, que existe uma ética educacional, que envolve toda a atividade da escola, desde as ações da equipe gestora até a comunidade que, em suas abrangências, direta ou indiretamente, faz parte do processo.

A ética faz parte, necessariamente, do projeto político-pedagógico e da função administrativa da escola. A aplicação da ética na gestão escolar implica mudança do comportamento relacional dos diferentes grupos e aprimoramento do processo de comunicação humana entre as partes envolvidas.

Neste sentido os Parâmetros Curriculares Nacionais (PCN/BRASIL, 1997, p. 28), ressalta que "por impregnarem toda a prática cotidiana da escola, os conteúdos de Ética priorizam o convívio escolar. São eles: Respeito mútuo, Justiça, Diálogo e Solidariedade".

Quanto ao respeito mútuo, os PCN (BRASIL, 1997, p. 29) diz que "o respeito é compreendido de forma unilateral: consideração, obediência, veneração de um pelo outro, sem que a recíproca seja verdadeira ou necessária."

O respeito mútuo expressa-se de várias formas complementares. Uma delas é o dever do respeito pela diferença e a exigência de ser respeitado na sua singularidade. Tal reciprocidade também deve valer entre pessoas que pertençam a 
um mesmo grupo e também o respeito pelos lugares públicos, como ruas e praças, também deriva do respeito mútuo. Como tais espaços pertencem a todos, preserválos, não sujá-los ou depredá-los é dever de cada um, porque também é direito de cada um poder desfrutá-los (BRASIL, 1997).

O tema justiça, segundo os PCN (BRASIL, 1997) vai muito além da dimensão legalista. A dimensão legal da justiça deve ser contemplada pelos cidadãos. Muitos, por não conhecerem certas leis, não percebem que são alvo de injustiças. Não conhecem seus direitos; se os conhecessem, teriam melhores condições de lutar para que fossem respeitados. Porém, a dimensão ética é insubstituível, precisamente para avaliar de forma crítica certas leis, para perceber como, por exemplo, por que alguns são mais privilegiados em detrimento de outros.

Outro fator importante na formação ética é o diálogo. Neste contexto, os PCN (BRASIL, 1997, p. 32) enfocam que "a comunicação entre os homens pode ser praticada em várias dimensões, que vão desde a cultura como um todo, até a conversa amena entre duas pessoas".

Dialogar pede capacidade de ouvir o outro e de se fazer entender, é valorizar a idéia do outro como forma de esclarecer conflitos e também saber dialogar. A escola é um lugar privilegiado onde se pode ensinar esse valor e aprender a traduzi-lo em ações e atitudes.

Quanto à solidariedade é importante entender que o enfoque a ser dado para esse tema é muito próximo da idéia de "generosidade": doar-se a alguém, ajudar desinteressadamente. A rigor, se todos fossem solidários, talvez nem se precisasse pensar em justiça: cada um daria o melhor de si para os outros. A força da virtude da solidariedade dispensa que se demonstre sua relevância para as relações interpessoais. Porém, o que pode, às vezes, passar despercebido são as formas de ser solidário. Não se é solidário apenas ajudando pessoas próximas ou engajando-se em campanhas de socorro a pessoas necessitadas (como depois de um terremoto ou enchente, por exemplo). Essas formas são genuína tradução da solidariedade humana, mas há outras. Uma delas, que vale sublinhar aqui, diretamente relacionada com o exercício da cidadania é a da participação no espaço público, na vida política. O exercício da cidadania não se traduz apenas pela defesa dos próprios interesses e direitos (embora tal defesa seja legítima), mas passa necessariamente pela solidariedade (por exemplo, atuar contra injustiças ou injúrias 
que outros estejam sofrendo). "É pelo menos o que se espera para que a democracia seja um regime político humanizado e não mera máquina burocrática" (BRASIL, 1997, p. 34).

Assim, a formação do educador deve partir de atitudes e ações relacionais desencadeadas pela dialética na gestão, na vivência e convivência do dia a dia da escola, provocando a transformação, não somente do desempenho intelectivo dos envolvidos, mas também dos comportamentos social, político, cultural e profissional.

Dessa forma, a ética, enquanto pensamento filosófico acerca do comportamento moral do homem se define como o estudo da "conduta ideal", esta decorrente de um conceito mais amplo, o de "homem ideal". Na atualidade, a ética consiste em ditar as qualidades das ações humanas, definindo-as como boas ou ruins, tendo como norte a razão da felicidade - "o soberano bem". Em resumo, a ética é uma ciência que estuda os valores e virtudes do homem, estabelecendo um conjunto de regras de conduta e de postura a serem observadas para que o convívio em sociedade se dê de forma ordenada e justa (VASQUEZ, ).

Cabe ao educador, em sua permanente formação, tornar-se cada vez melhor, pois quem gosta de ensinar ou apreciar o convívio com crianças e jovens não encontrará dificuldades em desobstruir caminhos para uma eficiente transmissão de conhecimento. O professor deve ter coragem de dizer aos seus alunos que acreditar, redescobrir a singeleza das coisas, o valor da família, a solidariedade, a lealdade, a finitude da vida e sua transcendência, como a breve aventura terrestre é o que se espera de um autêntico mestre que transmita além das lições escolares, a prática do respeito, da moral, da amizade, da tolerância e da compreensão.

Para isso, não basta conhecer a Ética, é preciso, acreditar e viver eticamente, preocupando-se com a formação de cidadãos conscientes, capazes de poder transformar o mundo, colocando-se a serviço da formação integral do educando, pois não há verdadeiro progresso, se não houver progresso moral. 


\section{Procedimentos metodológicos}

Este estudo orientou-se, predominantemente, por um enfoque bibliográfico e qualitativo, levando em consideração as palavras de Sacristán (2003, p. 18), quando afirma que "no movimento histórico das sociedades vão se estabelecendo procedimentos de depuração das informações culturais pedagógicas acumuladas e criam-se costumes de pensar cristalizados".

É no decorrer do processo de análise dos estudos dos diversos autores, que podemos verificar se as representações docentes ancoram-se nas três matrizes epistemológicas: humanistas, cognitivistas e sócio-históricas. Essas representações constituem-se de valores que convergem a influência dos ideais de aprendizagem interacionista, também reconhecidos como construtivistas, cujas raízes têm seu legado na história do pensamento pedagógico escolanovista. Esse fato pode ser identificado tanto em uma perspectiva humanista em que os docentes, ao referir-se ao aprendizado docente, centram-se nas relações interpessoais, no diálogo, na significação e associam o aprendizado à idéia de construção, processo e desenvolvimento.

Considera-se, portanto, neste trabalho, que a relevância da aprendizagem decorre da função docente do ensinar e do transmitir. Citam-se como condicionantes do aprendizado docente o esforço, a reflexão, a ética, o trabalho árduo, a fé.

Assim, baseados em Morin (2005); Freire (1996); Chauí (1988) e outros, este trabalho se conclui pelas fundamentações, compreendendo que a formação docente com compromisso ético parece atender grande parte das questões que, são imprescindíveis à melhor compreensão das mudanças na educação.

\section{Considerações finais}

Neste estudo aponta-se a necessidade de uma formação docente, considerando-se a ética numa condição cultural, envolvendo seus valores, suas condutas e suas linguagens, sua identidade social, assim como o reconhecimento dos saberes docentes que vêm legitimando "o ser e o fazer" dos professores no contexto do ensino. 
Os saberes docentes embasados na ética transformam os docentes em porta-vozes de uma cultura pedagógica, constituída de teorias, de princípios e das vivências empíricas mediadas pelas trajetórias sócio-afetivas.

É necessário considerar a formação docente em suas dimensões ética, política, cultural, epistemológica, pois não se pode mais pensar em uma política de formação docente que ignore as realidades histórico-sociais de formação.

No contexto geral da sociedade, identifica-se ética como atitude de respeito, dignidade, equidade, consciência, compromisso social, em um processo reflexivo nos valores e na prática profissional, no dia-a-dia. Acrescenta-se ainda, que ética pode ser definida como aquilo que é para aquilo que deve ser, de forma solidária e com cidadania.

A formação do educador com base na ética deve estar contemplada na construção do perfil do egresso. Por isso, cabe às unidades de ensino motivar os professores para exercer a integração da ética em suas disciplinas. Ela deve permear a formação docente porque hoje exige-se um educador com competência, lealdade, conhecimento, valores sociais e conhecimento do código da profissão.

Por outro lado, este educador estabelece uma relação com seu aluno embasada no respeito mútuo, onde o professor deve tratar o aluno como gostaria que o mesmo o tratasse. O docente deve conquistar os alunos por meio de habilidade, competência e postura profissional.

Discutir a formação docente e as diversas possibilidades de se trabalhar a ética na formação profissional é fundamental para que o professor valorize seu trabalho e entenda sua importância na formação ética de seus alunos por meio do bom exemplo e postura profissional.

\section{REFERÊNCIAS}

BRASIL. Ministério da Educação. Secretaria da Educação Fundamental. Parâmetros Curriculares Nacionais: 1a a 4⿳亠丷a série - Apresentação dos Temas Transversais e Ética. Brasília: MEC/SEF, 1997. v. 8.

CANDAU, V. M. Magistério - construção cotidiana. Petrópolis: Vozes, 1998.

CHAUÍ, Marilena. Convite a filosofia. 13. ed. São Paulo: Ática, 1988. 
FREIRE, Paulo. Pedagogia da autonomia: saberes necessários à prática educativa. 15. ed. São Paulo : Paz e Terra, 1996.

HERNANDEZ, Fernando. Transgressão e mudança na educação: os projetos de trabalho. Porto Alegre: ARTMED, 1998.

MELLO, Guiomar Namo de \& REGO, Teresa Cristina. Formação de Professores na América Latina e Caribe: A Busca por Inovação e Eficiência. Conferência Internacional: Desempenho de Professores na América Latina, Tempo de Novas Prioridades. Brasília; 2002.

MORIN, Edgar. Os Sete Saberes Necessários a Educação do futuro. 10.ed. São Paulo, Cortez, 2005.

RIOS, Terezinha Azeredo. Compreender e ensinar: por uma docência da melhor qualidade. São Paulo: Cortez, 2001.

SACRISTÁN, J. G. Pedagogias do Século XX. Trad. Fátima Murad. Porto Alegre: Artmed, 2003.

$\mathrm{SCHÖN}$, D. Educating the reflexive Practitioner. São Francisco; Jassey Bass, 1987.

VÁSQUEZ, Adolfo Sanches. Ética. Rio de Janeiro. Civilização Brasileira, 1998.

Recebido para publicação em: 16/06/09

Aceito: 30/01/10 